Bulletin of the AAS • Vol. 53, Issue 2

\title{
The Role of the Next Generation Lunar \\ Scientists and Engineers \\ (NextGen) Group in Lunar \\ Science and Exploration
}

Ryan N. Watkins ${ }^{1}$, Lillian R. Ostrach ${ }^{2}$, Sarah N. Valencia ${ }^{3}$, Amanda Stadermann ${ }^{4}$, Lora Bleacher ${ }^{5}$, Noah E. Petro ${ }^{5}$, Tess Caswell ${ }^{6}$, Amy Fagan ${ }^{7}$, Erica Jawin ${ }^{8}$, Heather Meyer ${ }^{9}$, Deanna Phillips ${ }^{10}$, Hannah O'Brien ${ }^{11}$,

Next Generation Lunar Scientists and Engineers Group

${ }^{1}$ Arctic Slope Regional Corporation Federal/NASA Headquarters,

${ }^{2}$ U.S. Geological Survey, Astrogeology Science Center,

${ }^{3}$ NASA Goddard Space Flight Center, University of Maryland College Park,

${ }^{4}$ University of Arizona Lunar and Planetary Laboratory, ${ }^{5}$ NASA Goddard Space Flight Center,

${ }^{6}$ NASA Johnson Space Center, ${ }^{7}$ Western Carolina University, ${ }^{8}$ Brown University,

${ }^{9}$ Johns Hopkins University Applied Physics Laboratory, ${ }^{10}$ University of Alabama Huntsville,

${ }^{11}$ University of Notre Dame

Published on: Mar 02, 2021

License: Creative Commons Attribution 4.0 International License (CC-BY 4.0). 


\section{ABSTRACT}

Founded in 2008, the Next Generation Lunar Scientists and Engineers (NextGen) is a group of students and early career professionals who have a vision and passion for lunar science and exploration. NextGen organizes professional development opportunities through workshops and networking events that are designed to provide resources and training for scientists and engineers so that they are prepared to lead international lunar science and exploration programs. NextGen also provides a network of professional support and opportunities for the younger generation to lead in the field and to learn from more experienced generations of lunar scientists and engineers. Members of NextGen are actively engaged in scientific research, mission formulation/execution, community outreach, and professional activities. With the United States on the brink of a new era of lunar exploration, and many international space agencies preparing to send spacecraft to the Moon, NASA and the lunar community have recognized the importance of training and nurturing the next generation of lunar scientists and engineers. As the future workforce, it is imperative that students and early career professionals receive continued and increased support from NASA, industry, and the lunar community as a whole.

\section{Introduction}

Both NASA and the international community have long recognized the necessity to encourage and train the next generation of lunar scientists and engineers [1],[2]]. Founded in 2008, the Next Generation Lunar Scientists and Engineers (NGLSE or "NextGen") Group is an assemblage of graduate students, postdocs, and early career scientists and engineers who have a passion and vision for lunar science and exploration, and who are the future lunar workforce for NASA, academia, and industry. The primary purpose of NextGen is to provide guidance and networking opportunities to early career lunar students and professionals, as well as to foster collaboration with other groups within the lunar community [2]].

NextGen fosters the development of the next generation of lunar professionals by providing workshops and career training, offering a support network for young lunar scientists and engineers, and providing opportunities for leadership and for learning from the more experienced generation of lunar researchers. NextGen is, and has been for the last 13 years, providing NASA and industry with a workforce that is focused on and experienced with the integration of science and engineering as it pertains to human and robotic lunar exploration-enabled science. The goal of this paper is to 
highlight the fact that NextGen exists as a vibrant and enthusiastic group of young lunar scientists and engineers who have been contributing valuable knowledge and skills to the planetary community since 2008, and who strive to place the Moon at the forefront of planetary exploration. This paper also highlights the importance of having a group solely dedicated to fostering the next generation lunar workforce. We discuss the demographics, history, and activities of NextGen, as well as highlight some of the research areas and professional activities with which our members are involved.

\section{History}

The NextGen group was founded informally in 2008 by early career lunar researchers and education and public outreach professionals as a grass-roots effort aimed at fostering the growing community of early career lunar scientists and engineers [1]. Around that time, NASA's Constellation Program was preparing for future US orbital and landed spacecraft to return to the Moon. Combined with an increase in funding opportunities in lunar science and lunar exploration interest within the international community, the timing was ideal to build this community. Although the plans for US crewed missions were canceled and lunar science funding has fluctuated since that time, recent lunar missions have continued to attract students and early career professionals who are interested in lunar science and exploration. Missions such as the Lunar Reconnaissance Orbiter (LRO), Lunar Atmosphere and Dust Environment Explorer (LADEE), Gravity Recovery and Interior Laboratory (GRAIL), India's Chandrayaan-1 mission, Acceleration, Reconnection, Turbulence, and Electrodynamics of the Moon's Interaction with the Sun (ARTEMIS), and the Chinese Chang'E missions, together with NASA research programs such as the Lunar Data Analysis Program (LDAP) and Planetary Science and Technology Through Analog Research (PSTAR), have all contributed to a recent increase in the number of early career scientists and engineers who are active in the lunar community. Furthermore, with a recent renewed interest in returning to the surface of the Moon through the Artemis and Commercial Lunar Payload Services (CLPS) programs, the cohort of young lunar scientists and engineers is likely to continue growing in the next several years.

By 2011, interest in NextGen had grown and the group consisted of nearly 200 members from academia, industry, and NASA personnel. The group's founders applied for and received NASA funding to design and fund experience-building and networking activities for NextGen group members. These activities included professional development workshops and community-building events that served to better equip the 
members to contribute to the success of the lunar program [2] and are described in more detail in Section 4.

In addition to early NASA support, NextGen received support from the then-NASA Lunar Science Institute (NSLI; now the Solar System Exploration Research Virtual Institute; SSERVI) to host workshops in association with major conferences featuring lunar science content. The NLSI also provided funding for NextGen to offer travel grants for students to attend these conferences. The first official NextGen workshop was held in 2010 in association with the 2010 NASA Lunar Science Forum (now the SSERVI Exploration Science Forum; ESF)[]].

In 2014, a group of NextGen members gave a presentation at the Brown-Vernadsky Microsymposium (held the weekend prior to the annual Lunar and Planetary Science Conference; LPSC) on the NextGen role in human space exploration and the need to bridge the gap between the Apollo generation and the NextGen generation. As a result of this presentation, the lunar community at large embraced the idea of "bridging the gap" and creating a link between NextGen and more established lunar professionals [4]. The Executive Committee of the Lunar Exploration Analysis Group (LEAG) expressed a desire to include NextGen members in their meetings and activities, and a strong collaborative bond was formed between the two groups. The support and backing of LEAG has provided NextGen with crucial mentorship and guidance from established members of the scientific community. In addition, LEAG created a spot on their Executive Committee for a NextGen member to fill, allowing the younger generation to lend a voice to lunar activities and policies. Serving on the LEAG Executive Committee also provides NextGen with an opportunity to learn how to compose findings that will be used to inform decisions regarding the science and operational priorities of lunar missions, thereby better preparing us to be the next leaders of lunar exploration. Mentorship from members of LEAG is essential for bridging generational knowledge and experience gaps, as well as for preparing the NextGen to lead and train future generations. Such experiences are equipping the NextGen to be able to call upon the knowledge of the Apollo generation to support the next human lunar exploration program while also bringing our own perspectives and innovation to lunar science and engineering. Continued support, guidance, and participation from more experienced LEAG members, especially those involved with Apollo, will reduce the knowledge and experience gaps between generations of lunar leaders. 
Although NextGen currently does not receive financial support through grants or other lunar-related groups directly, the group has been and continues to be strongly supported by both SSERVI and LEAG. These two groups both provide travel grants (e.g., the B. Ray Hawke Next Lunar Generation Career Development Award and the Larry Taylor Travel Fund) for students and postdocs to attend meetings such as the SSERVI Exploration Science Forum (ESF) and the LEAG Annual Meeting.

\section{Structure and Demographics}

The NextGen Group is open to anyone, regardless of the planetary body they primarily study, but with special emphasis on individuals interested in the Moon who are in college or graduate school, early in their career ( $<10$ years post-terminal degree), or new to planetary science and engineering. Many mid-to-late career lunar experts, including early members of NextGen who have advanced in their careers, are also active in the group, especially in workshop settings where the advice and guidance of experienced scientists and engineers is invited, welcomed, and encouraged. They routinely make themselves available for discussion and networking activities and have pro-actively fostered a welcoming environment for NextGen members at workshops and conferences. As of the time of writing, our membership remains high $(>100$ members) and is seeing continued growth amidst the Administration's directive to return to the Moon.

A recent survey was distributed to NextGen and LEAG members to gauge the participation and demographics of the group, as well as satisfaction with events and communications. There are currently $>100$ members who receive communications via email, our website, Facebook , and other social media platforms. Of those members, 91 responded to the 17-question survey. As we will discuss below, several survey respondents were mid-to-late career who are invited and encouraged to attend our events. The survey indicated that $64 \%$ of individuals who receive NextGen communications are continually active in workshops and other NextGen-sponsored events, therefore we believe that these responses from active NextGen members adequately reflect the demographics and satisfaction of the NextGen group as a whole.

The survey indicated that $92 \%$ of respondents identify as scientists and $8 \%$ as engineers (Figure 1). While the majority of the group's members identify as scientists, NextGen maintains connections with Boeing, the Jet Propulsion Laboratory (JPL), Goddard Space Flight Center (GSFC) and various commercial companies (Moon Express, Blue Origin, Boeing, etc.), from which we seek to recruit new members who are engineers by training. 
Of the survey respondents, $46 \%$ are early career $(<10$ years post-terminal degree; includes postdocs), and 19\% are students. Another 19\% are mid-career (10-20 years post-terminal degree), and $15 \%$ are late-career (20+ years post-terminal degree) (Figure 1). The remaining $1 \%$ are retired or on a career sabbatical. While NextGen is typically geared towards students and early-career professionals, we open most of our activities and communications up to all lunar scientists and engineers, hence the survey participation from individuals who have been in the field longer than 10 years.

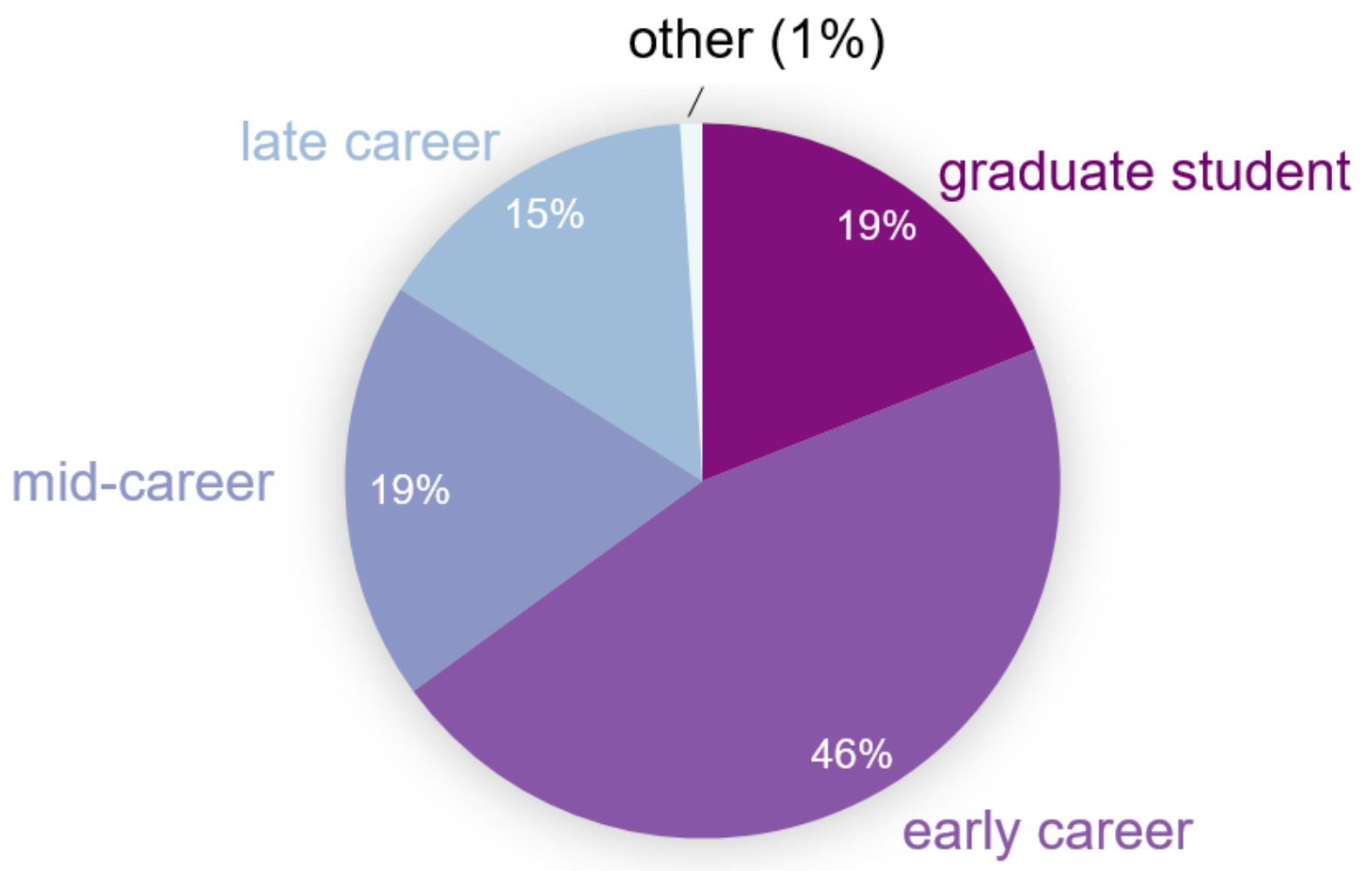

Figure 1: Breakdown of the current career stages for NextGen members. Early career $=<10$ years post-terminal degree (includes postdocs), mid-career $=10-20$ years post-terminal degree, late career $=20+$ years post-terminal degree

$21 \%$ of survey respondents have been active in the group for $5+$ years (Figure 2). Another $36 \%$ indicated that they receive NextGen communications but have yet to participate in meetings or workshops; many of these are likely students who are new to the field and who have not had many opportunities to attend NextGen events. 14\% are mid-to-late career individuals who occasionally participate in early-career focused meetings and workshops, and who receive NextGen-related communications and wanted to provide support and feedback to our group by responding to the survey. Approximately 15\% of respondents have been active for two years or less, which highlights the recent growth the NextGen group has seen as the Moon moves once again to the forefront of planetary exploration. 


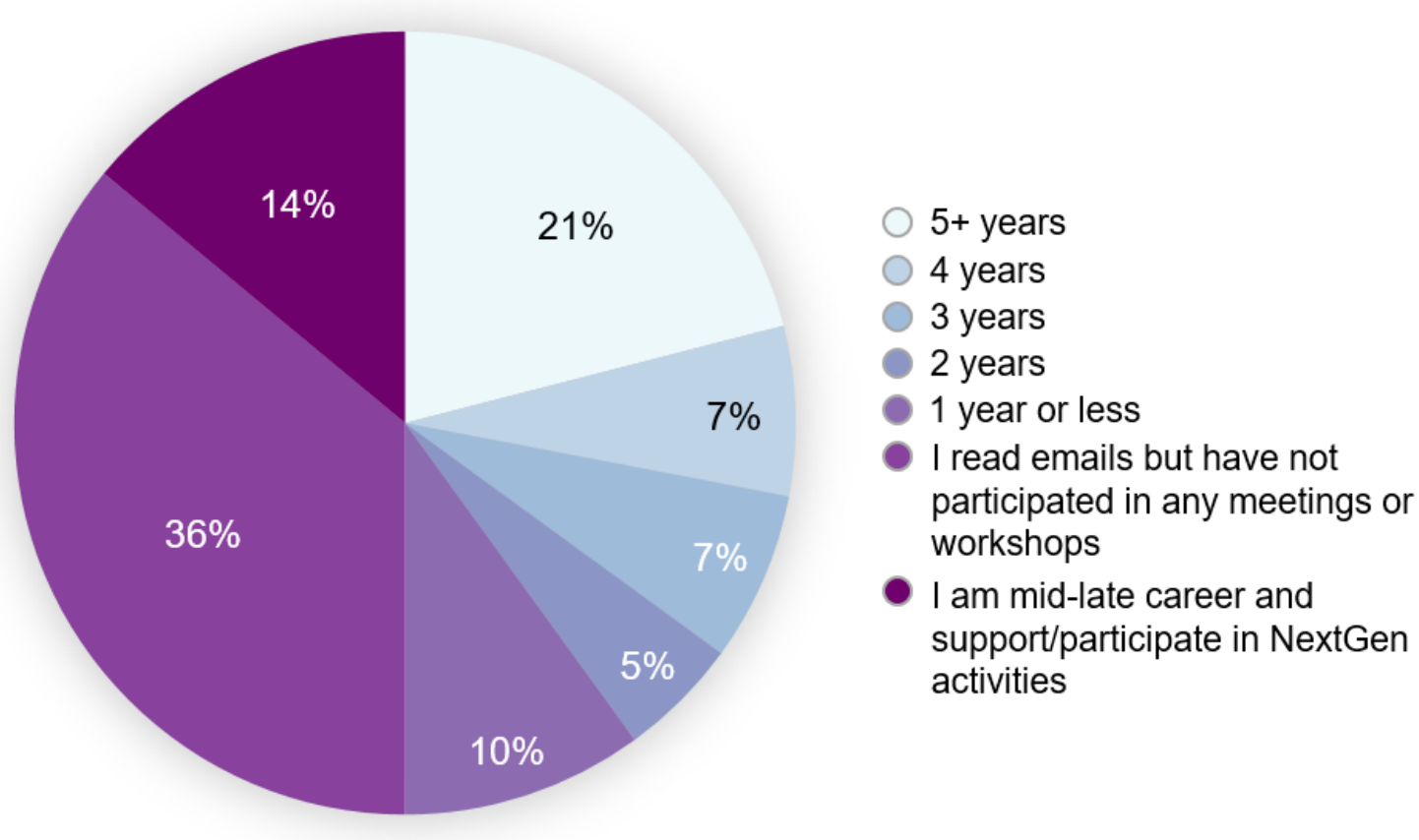

Figure 2: Breakdown of number of years NextGen members have been active in the group.

NextGen welcomes international students and early career individuals, although our international membership is currently low (and most of our international members are based at U.S. institutions). We are actively considering methods to boost international participation, specifically through an improved online presence (e.g., website, Twitter, Facebook, and email). Our plans for increasing our online presence include hosting virtual workshops (see Section 4), and although the time zone differences may not allow international students to participate in all of them, we plan on posting recorded versions of the workshops online to have available for international members.

The NextGen leadership structure consists of a core group of members, the "Organizing Committee" (OC), who consistently assist in organizing and advertising workshops and in communicating lunar news and job information. The Organizing Committee currently consists of 9 graduate students, postdocs, and early career professionals who have been active members of NextGen for a year or more, and who maintain an active role in LEAG and other lunar-related activities and organizations (e.g., advocacy, review panels, education and public outreach, etc.). The OC is currently advised by two of the original founders of the NextGen group, Dr. Noah Petro and Lora Bleacher. Every year or two, the more senior members of the Organizing Committee recruit graduate students who begin assisting with workshop planning, and who are interested in taking on a more active role with NextGen. These recruitment 
efforts allow for a seamless transition as more senior OC members transition to the role of advisor or cease having an active role within the NextGen leadership structure.

\section{NextGen Workshops and Professional Activities}

Workshops and professional activities are a central part of the NextGen community [2] ] [3]. The United States is at the beginning of a new era of lunar exploration, and NASA, SSERVI, and LEAG have all recognized the importance of training and nurturing the next generation of lunar scientists and engineers. Additionally, many other countries (e.g., China, Korea, India, Russia, Israel, and Japan) have sent or are planning to send spacecraft to the Moon, so it is important that the youngest generation of lunar professionals are prepared to participate in and lead these and future lunar programs. NextGen-sponsored workshops are designed to provide valuable resources and training for scientists and engineers so that they are prepared to lead these lunar science and exploration programs. These workshops are imperative because the topics being offered are not regularly covered by any other groups in the lunar community, and they provide valuable training that will enable early career professionals to become leaders in the field. Importantly, NextGen strives to bring scientists and engineers together in order to bridge the gap in communication and collaboration between the two groups, which is critical to the sustainability of successful lunar exploration and scientific missions.

NextGen-sponsored workshops are typically held in conjunction with conferences and meetings, since these are events that naturally bring together new and experienced lunar scientists and engineers, and provide opportunities for networking and collaboration. Additionally, because NextGen does not currently receive funding support to convene these workshops, holding them concurrently with well-attended conferences and meetings enables greater participation by early career scientists and engineers who may not have otherwise attended (due to limitations/lack of travel funding, time, etc.), and by senior professionals who may otherwise be unable to lend their time to mentor early career participants. Generally, workshop topics are focused on professional development (see next section) and on informing early career scientists and engineers about opportunities available to them in the planetary science field. The following sub-sections describe past workshops and professional development activities that NextGen has sponsored, as well as participation, satisfaction, and current and future activities. 


\subsection{Past Activities}

The first official NextGen workshop was held in 2010, a day prior to the beginning of the annual NASA Lunar Science Forum (now SSERVI Exploration Science Forum). The workshop focused on how to design presentations and how to effectively communicate science and engineering to peers and to the public. After the workshop, a survey of participants revealed that $91 \%$ of the participants believed the workshop was effective []ㅡ. Since that time, workshops have been offered in conjunction with scientific conferences almost every year, and, after the restructuring of NLSI to SSERVI, have primarily been held during the annual Lunar and Planetary Science Conference (Figure 3).

Workshop topics are selected based on the needs of NextGen members, as indicated through surveys distributed each year, or as decided upon through discussions among the Organizing Committee. Past workshop topics, the year they were held, and the meeting they were held at are listed in Table 1 (note that the 2020 LPSC workshop on "Communicating your Science to the Public" was cancelled due to the COVID-19 pandemic). While the topics are catered towards students and early career professionals, most of the workshops are open to anyone in the planetary science community, regardless of career stage or primary research area. Workshop attendance generally ranges from a dozen to $\sim 50$ people, depending on the topic and the size of the conference, and many of the topics listed in Table 1 also attract the interest of more established professionals.

Table 1: NextGen sponsored workshop topics held since 2010.

\begin{tabular}{|l|l|l|}
\hline Workshop Topic & Year & Location \\
\hline $\begin{array}{l}\text { Communicating Your Science } \\
\text { Effectively }\end{array}$ & $2010 ; 2018$ & NLSI; LPSC \\
\hline Speaking with the Media & 2011 & NLSI \\
\hline Proposal Writing & $2011 ; 2013$ & LPSC; virtual \\
\hline Mission Participation & 2014 & ESF \\
\hline Writing and Publication Process & 2015 & LPSC \\
\hline
\end{tabular}




\begin{tabular}{|l|l|l|}
\hline $\begin{array}{l}\text { Scientists and Engineers: } \\
\text { Learning to Work Together }\end{array}$ & 2016 & LPSC \\
\hline Career Paths & 2017 & LPSC \\
\hline $\begin{array}{l}\text { Preparing for Job Talks and } \\
\text { Interviews }\end{array}$ & 2018 & virtual \\
\hline $\begin{array}{l}\text { Work/Life Balance } \\
\text { Navigating the ROSES R\&A } \\
\text { Structure }\end{array}$ & 2019 & virtual \\
\hline $\begin{array}{l}\text { Using Social Media to Share } \\
\text { Your Science }\end{array}$ & 2019 & virtual \\
\hline $\begin{array}{l}\text { Eemmunicating } \\
\text { the Publie }\end{array}$ & $\mathbf{z 0 2 0}$ & LPSC \\
\hline
\end{tabular}

${ }^{1}$ The 2012 LPSC gathering was an informal networking event

2Jointly sponsored with the Lunar and Planetary Institute.

${ }^{3}$ The 2020 LPSC event was cancelled due to COVID-19.

The format of each workshop varies. Many workshops, such as Proposal Writing, the Writing and Publication Process, Mission Participation, and Career Paths, have involved panel discussions (Figure 3a). Panelists are typically senior members of the lunar science community with significant experience on the selected topic (again, reflecting the participation of mid-to-late career individuals in NextGen) and are invited by the Organizing Committee. For the Mission Participation workshop, panelists were members of various mission teams, and they discussed different avenues for becoming involved with current and future lunar missions. The panel on career paths included individuals from academia, industry, government, and non-profit organizations. Each panelist shared the path they took to get to their current position, why they chose that position, and what it was like working in each various area of planetary science. 

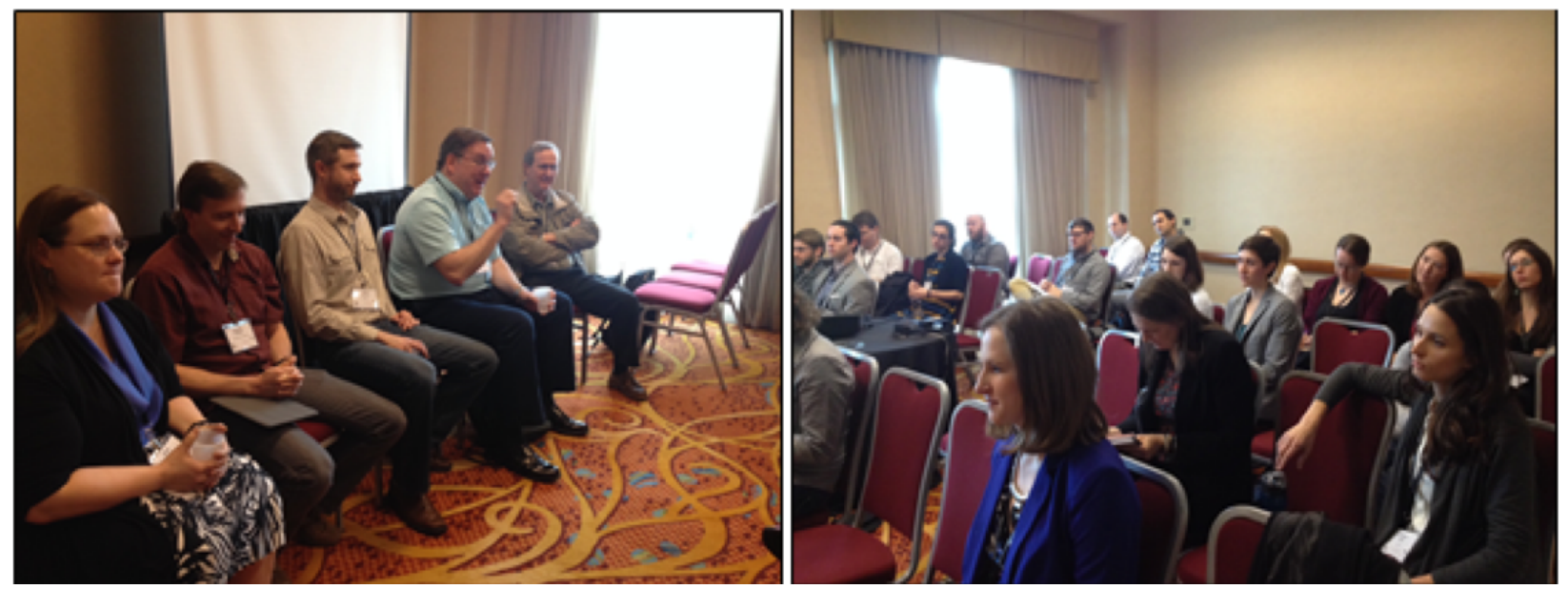

Figure 3: NextGen members participating in the 2015 workshop on Writing and Publishing Scientific Papers, held at the annual Lunar and Planetary Science Conference. This workshop featured a panel discussion (left) and an open Q\&A time. Photo posted with permission of participants.

Other workshops consist of a presentation given by one or two individuals who are experts on the topic. For example, the recent 2019 NextGen-sponsored virtual workshop on "Navigating the ROSES R\&A Structure" consisted of a presentation given by NASA's Science Mission Directorate's Lead for Research, Max Bernstein. Dr. Bernstein walked participants through understanding the structure of Research and Analysis Programs within the NASA ROSES program, what the important documents are, and what the various breakdown of solicitations would be for that year. This workshop provided opportunities for early career scientists to learn about important tools they will need as they advance in their careers. In 2016, the workshop "Scientists and Engineers: Learning to Work Together" featured Lee Graham from NASA Johnson Space Center, who is part of a program (JSC Systems Engineering and Project Management Advancement Program) geared towards integrating scientist Principal Investigators with engineering teams so the two groups learn how to effectively communicate. During his presentation, he discussed various definitions of systems engineering and how scientists and engineers can learn from each other and better work together. Systems engineering is an interdisciplinary field of engineering that focuses on optimizing the design and management of complex engineering systems (e.g., planetary missions) over their life cycles (e.g., [ㅁ] ]). Science objectives drive mission design, so the Project PI (scientist) and Project Systems Engineer must communicate and coordinate all the time, from initial proposal development through lifetime of the project.

Every workshop, regardless of the format, has open Q\&A time at the end. Although many workshops encourage questions during the presentations or panel discussions, a dedicated discussion time provides the participants with an opportunity to ask 
questions, directly interact with the presenters, and to share their own experience, knowledge, and advice.

\subsection{Workshop Participation and Satisfaction}

About 33\% of survey respondents have participated in one or more of the workshops stated above. Of workshop participants who identify as students or early career, most were very satisfied (28\%) or satisfied (45\%) with the quality of in-person NextGensponsored workshops, with the remaining $27 \%$ feeling neutral. No early career or student participants felt negatively toward the workshops. Figures for the quality of NextGen-sponsored virtual workshops are similar, again with no dissatisfaction reported: $24 \%$ were very satisfied, $48 \%$ were satisfied, and $28 \%$ felt neutral.

According to the survey, the most frequently attended workshops ( $42 \%$ of respondents who have attended workshops) were the 2011 and 2013 workshops on Proposal Writing, followed very closely (38\%) by the 2017 Career Paths and 2019 Work/Life Balance workshops. Several participants suggested holding certain workshops (e.g. proposal writing) more frequently since many topics never cease to be relevant to the NextGen community and since new members join yearly. Additionally, topics such as proposal writing are not always provided by member institutions or are no longer regularly offered to the planetary science community (for instance, NASA used to hold a proposal writing workshop the weekend prior to LPSC, but this workshop has not been offered for many years). Survey respondents also suggested posting recorded videos of the workshops, or making the workshops accessible to remote participants who are unable to attend LPSC. When possible, we have begun archiving recorded workshops on our website, with permission of the presenters and attendees. Others suggested holding a workshop in conjunction with the annual LEAG meeting, which may also encourage more students and early career professionals to attend LEAG on an annual basis. Similarly, others suggested NextGen events at international conferences since lunar exploration is not solely US-led. We are actively working to incorporate these suggestions into our future plans.

\subsection{Current and Future Activities}

Aside from the annual LSPC workshop, NextGen holds informal gatherings at various conferences and meetings. These gatherings are usually in the form of dinners or networking events. For example, there is a joint NextGen-LEAG dinner at the annual LEAG meeting. This dinner is open to both early and mid-to-late career professionals and is an ideal setting for networking in an informal and low-stress environment. In 
2018, many commercial company representatives, including the CEO of Moon Express, even attended the dinner and spent time interacting with NextGen attendees. In 2019, the chair of LEAG joined just to express his support and appreciation for the group.

One of the largest informal events in recent NextGen history has been a joint LEAGNextGen networking event at LPSC (Figure 4). The purpose of this event is to facilitate dialogue between NextGen and more seasoned experts in the lunar community in a relaxed, informal setting. The first annual networking event, spearheaded by the thenLEAG chair, Clive Neal, was held in 2015 and was advertised via word-of-mouth only. This event was widely attended and many new lunar professionals had the chance to talk with experts in the lunar community that they otherwise may have been hesitant to approach [4]. The event was formally advertised in subsequent years, and has now drawn crowds of $150+$, with $50 \%$ of survey respondents having attended at least one of these annual events. During the event, mid-to-late career participants are strongly encouraged to interact with students and early career professionals, and vice versa. The survey revealed that $69 \%$ of student and early-career attendees and $88 \%$ of mid-tolate career attendees have been satisfied or highly satisfied with this event. Several participants suggested that we continue to find new and creative ways to bridge the gap and increase communications between the younger or less experienced generation and the more experienced individuals at the event.

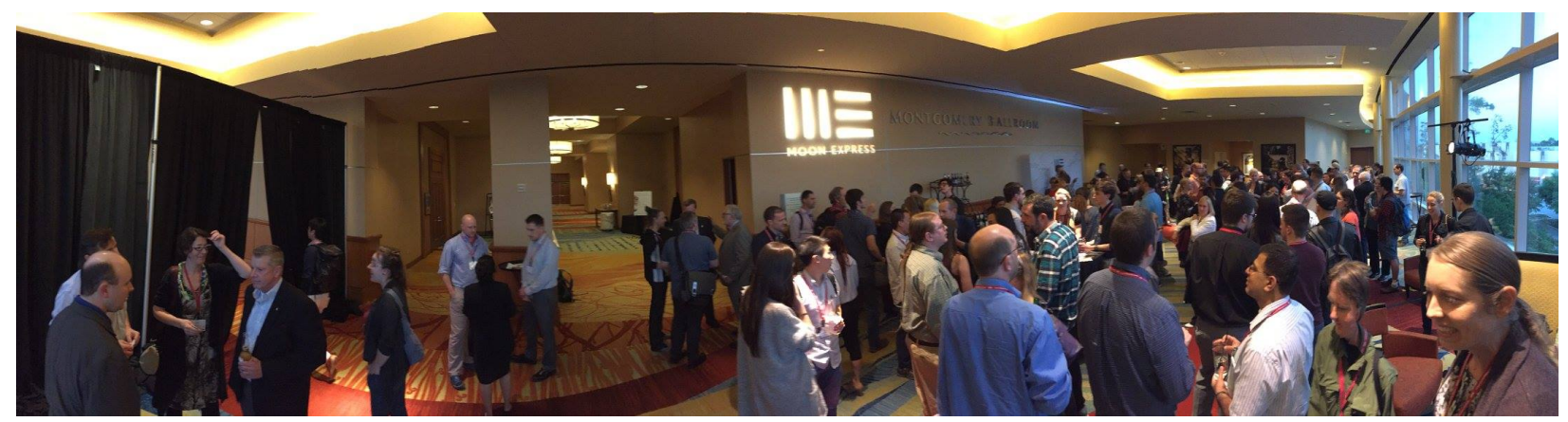

Figure 4: Participants at the 2017 LPSC Networking event, which was sponsored by Moon Express.

In addition to continuing with workshops held at LPSC, the Organizing Committee has started offering more virtual workshops in order to cover additional topics and to encourage participation from more individuals. A 2018 survey of NextGen members showed that $92 \%$ of early career and student respondents would be interested in participating in virtual workshops, so we began providing virtual options as a way to offer more professional development opportunities throughout each year, and to reach additional members who may be unable to attend in-person workshops. These virtual workshops do not replace the workshops held at conferences, as we see incredible value in interacting and networking with our colleagues face-to-face. Virtual 
workshops serve as a valuable tool in increasing the percentage of NextGen members (across all career stages) who are actively participating in the group's events (see Section 3). Given the fatigue brought on by so many virtual meetings in the midst of the COVID-19 pandemic, we have replaced virtual workshops (temporarily) with informal gatherings for NextGen members to drop in and get to know each other and the OC. As the group continues to grow, we also hope to begin offering workshops at other conferences that have a sizeable contingent of NextGen members in attendance (e.g., LEAG, ESF, etc.), including some international conferences (e.g., Annual Meeting of the Meteoritical Society, the European Lunar Symposium, European Planetary Science Congress, etc.).

\section{Research Highlights}

While NextGen workshops are focused on providing professional development for the whole scientist (e.g., from communicating effectively to proposal writing and publishing), the fruit of these opportunities is revealed through successful research programs and involvement in the lunar science and exploration community. Scientific results from recent lunar missions, integrated with existing data sets and new analyses of lunar meteorites and Apollo samples, have continued to provide us with rich data sets that are unraveling the mysteries of the Moon. NextGen members are actively engaged in lunar science research at their respective institutions. Several NextGen members also have active roles on past and current SSERVI teams, and many are actively involved with the Apollo Next Generation Sample Analysis program, which is currently analyzing previously unopened Apollo 17 samples.

This section highlights a small subset of the research areas in which NextGen scientists have made, and are currently making, valuable contributions to the community. The point of this section is to show the breadth and depth of research conducted by NextGen members and highlight the fact that NextGen-led research spans the range of planetary geologic processes. The highlighted research was selfreported; members were requested to voluntarily provide a brief description of research they have conducted in the past or are currently working on. These lists are not exhaustive, but rather serve to demonstrate that NextGen members are engaged in lunar science research and exploration initiatives. Research areas cover the broad themes of volcanism, tectonism, geophysics, impact cratering processes, sample analysis, geology, regolith processes, exploration strategies, and more. Note: Many of the research projects highlighted here span more than one of these themes; for simplicity we only list each topic under the theme it most broadly fits under. The 
reader is referred to the cited references for more details and results regarding each scientific investigation. Additionally, we omit citations of works led by more senior professionals for the sake of highlighting efforts that have significant NextGen leadership and involvement.

\subsection{Volcanism}

Recent lunar missions have revealed further complexity regarding the nature and timing of lunar volcanism, which holds important implications for the thermal and compositional evolution of the Moon. Research by NextGen members regarding lunar volcanism spans the following:

- Conducting photometric investigations of LRO Camera (LROC) images, coupled with soil composition data from returned samples, to place compositional constraints on silicic volcanic regions, a rare type of volcanism on the Moon [ㅁ] ].

- Understanding the history of volcanism and volcanic emplacement by investigating lunar lava pits (e.g., [7]) and the distribution of ancient buried volcanic materials (cryptomare) in the lunar South Pole-Aitken Basin (e.g., [ㅁ][ㅁ]).

- Analysis of the geographical extent and surface properties of the Apennine Bench Formation in order to better understand the formation and distributions of KREEP basalts $[\underline{10}]$.

- Characterizing endmember volcanism on the Moon; specifically, (1) understanding the eruptive history and exploration potential of the largest explosive eruption on the Moon, located at the Aristarchus Plateau [11], (2) using spectroscopy to analyze compositional and mineralogical variations within dark mantle deposits [12], and (3) using radar to understand the history of lunar volcanic features [13] [14].

\subsection{Impact Cratering Processes}

The Moon is an easily accessible target for studying impact processes and for constraining the impact history of the inner Solar System. High-resolution imaging from LROC has allowed detailed investigations into cratering mechanisms at unprecedented scales. Research into impact cratering processes being conducted by NextGen members includes:

- Characterizing impact melt deposits. This theme includes geologic mapping of impact melts at complex craters (e.g., [티]), including previously unrecognized melt deposits [16] and characterizing putative impact melt outcrops around the periphery of Mare Crisium [17]. 
- Examining the global distribution and comparison of impact melt on the Moon and Mercury using remotely sensed data from recent missions. Estimation of melt volumes and characterization of melt deposit morphologies facilitate improved understanding of the effects of planetary variables during the impact process and test accepted melt-generation models (e.g., [18][19]).

- Investigating spatial density differences for 5-10 km diameter impact craters to explore regional resurfacing, the presence of secondary crater populations created by basin-sized impacts, and to better understand crater saturation equilibrium [20].

- Using LROC data to quantify the effect of crater measurements on determining relative and absolute ages for geologic units, which are sensitive to the solar incidence angle of images, the underlying slope of the terrain, and many other

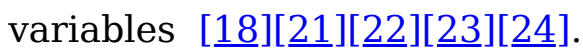

- Examining the difficulties of identifying primary craters and assessing effects of different crater measurement techniques on absolute model age-dating for the lunar mare, with development of a statistical method to distinguish units on the basis of crater spatial density [25][26] $[\underline{27}]$.

- Understanding the morphology, shapes, and degradation rates of craters and generating standardized mathematical ways to describe crater forms [료][르].

- Investigating the distribution and origins of light plains deposits to provide insight into the basin formation process and basin stratigraphy, and to inform sample interpretations [21] [30].

\subsection{Geology, Mineralogy, and Petrology}

Understanding the diversity of lunar rocks, how they formed, and their distribution across the lunar surface is critical to understanding the structure and evolution of the lunar crust. NextGen-led studies into the composition of various lunar rock types include:

- Constraining the mineralogical character of impact melt deposits, along with their detailed geologic context on large spatial scales. Multiple exposures of Mg-spinel lithologies, a recently discovered rock type on the Moon, have been detected [1ㅣ] , as well as a newly detected, mineralogically distinct, sinuous melt feature at Copernicus crater [32].

- Investigating the structure and evolution of the South Pole-Aitken Basin by probing the mineralogy of materials (using Moon Mineralogy Mapper, $\mathrm{M}^{3}$, data) that were excavated during the SPA-forming impact, as well as an unusual resurfaced zone in 
the basin center that may be a form of long-lived, impact-induced volcanism [ $\underline{33}][\underline{34}]$ [35].

- Producing nearly global maps of abundances of plagioclase, low- and high-calcium pyroxene, and olivine, and using these maps to study the vertical composition of the lunar crust by studying central peaks and basin rings [ㅎ6][37].

\subsection{Geophysics And Atmospheric Science}

Using recent data from GRAIL, ARTEMIS, and LRO, NextGen members are investigating geophysical properties of the lunar surface and atmosphere. Investigations include the following:

- Modeling efforts to constrain the interior structure of the Moon. These efforts include a geophysical forward-model capturing magnetic induction from conducting layers within a vacuum, and a plasma induction model capturing the kinetic plasma environment within the wake cavity around a conducting Moon [요][39]].

- Understanding the thermal emission of the lunar surface, and how physical and compositional properties can be interpreted from that data (e.g., [40][41][42]).

- Modeling the solar wind-derived exosphere by constraining the degassing of atoms and molecules from the surface, and comparing these results to $\mathrm{M}^{3}$ observations and Lunar Atmospheric Composition Experiment (LACE) measurements (e.g., [4]]).

\subsection{Volatiles}

Understanding the composition, distribution, source, and nature of lunar volatiles will greatly inform the inventory of volatiles in the Solar System. Volatiles are also essential to exploration; water is a valuable resource that could be mined in-situ and used for life support and propellant. Members of NextGen are involved with volatile research, including:

- Developing and applying numerical models to (i) learn how to read the geological record preserved by cold-trapped polar volatiles, and (ii) understand how volatile transport, loss and sequestration take place. Specific investigations include understanding the transport and deposition of volatiles in the aftermath of a lunar comet impact [44], and the influence of small-scale surface roughness on volatile transport [4드].

- Temperature programmed desorption studies of water interactions with Apollo samples [46] and how the findings of this work can be applied to spacecraft observations of the lunar surface [나] [ $\underline{48}]$. 
- Using LROC images and Mini-RF radar data to identify potential ice-rich craters at the lunar north pole (e.g., [49]).

- Studying the alteration of volatile-rich samples at different storage conditions to constrain their scientific requirements for future sample return missions from the poles [뭉.

- Detecting geologically young craters using ultraviolet observations in permanently shadowed regions [1] .

- Providing a new calibration for the Lunar Orbiter Laser Altimeter (LOLA) to study reflectance in permanently shadowed regions [르].

\subsection{Regolith Processes and Space Weathering}

Our view of the lunar regolith and processes that contribute to its formation, evolution, and modification, including space weathering, has greatly changed with recent data sets. Using high-resolution data from recent missions, NextGen professionals are actively conducting investigations such as:

- Analysis of boulder distributions around lunar impact craters to inform the rate at which rocks become regolith, and to understand how the density of boulders produced by an impact event changes with varying crater properties [토] [ $\underline{54}]$.

- Understanding the effects of shaking on compositional sorting within a granular regolith. Work by [5ㅡㄹ has experimentally tested the possibility of mechanical segregation of particles in the lunar regolith, the results of which provide at least one explanation toward understanding the inconsistencies between lunar remote sensing datasets and are important for future spacecraft sample return missions.

- Coupling LROC Narrow Angle Camera (NAC) photometry with Hapke modeling to determine the effects of rocket exhaust on the reflectance and physical properties of the lunar regolith at spacecraft landing sites, with applications for planning for

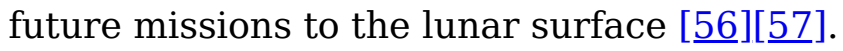

\subsection{Sample Analysis}

Sample-based research is truly the "gift that keeps on giving." New discoveries and insights related to fundamental Solar System processes are continually being made through re-analysis of Apollo samples, as well as newly discovered lunar meteorites, using the latest analytical techniques and instruments. A few NextGen members are actively involved in analyzing both Apollo and lunar meteorite samples to better understand the composition and petrogenesis of the lunar crust and to fill in knowledge gaps regarding the geologic history of the Moon. 
- Geochemical and petrological analyses of igneous and impact melt samples from the Apollo missions are being used to better assess the age, composition, and variability of lunar materials at the surface [묘 $[\underline{59}]$.

- Relict clasts of meteoritic materials preserved in regolith breccias have been analyzed, as they record the temporal history of the types of impactors bombarding the lunar surface, circa $2 \mathrm{Ga}[\underline{60}]$.

- Lunar meteorite samples are being used to study volcanic processes at and below the lunar surface. In particular, the crystallization sequence of a shallow magma chamber is being examined through various lithologies in chemically related meteorites [두].

- The petrology and petrogenesis of potentially related components in complex lunar sample 12013 have been examined. This work has implications for the formation mechanism of granite on the lunar surface [드][ㅎ3].

- Apollo samples have been used to understand the timing of Moon formation, via hafnium-tungsten isotopes [64].

\subsection{Field Studies}

Field-based research on Earth focuses on preparing for future human and robotic exploration of the Moon. Many NextGen scientists and engineers are active members of teams that conduct scientifically-driven field exploration campaigns to test instruments and rovers, gather scientific data, and develop tools for future human exploration. Some examples include:

- Developing and testing tools for field geologic investigations on Earth and on the Moon (e.g., [ㅌ5][ㅎ6]).

- Participation in Desert Research and Technology Studies (RATS; [65]) and the NASA Extreme Environment Mission Operations (NEEMO; [ㅎ6]).

\subsection{Engineering and ISRU}

Apart from scientific research, NextGen members are visionaries and are proactively involved in various engineering and in-situ resource utilization projects and companies. For example, NextGen engineers founded Lunar8 (http://www.lunar8.space/), a company whose goal is to build a reusable lunar lander that will deliver cargo, modules, and people from lunar orbit to the surface of the Moon. Another NextGen member founded Crow Industries (http://crowindustriesinc.com/), which will design, develop, and deploy technologies (with emphasis on ISRU) to explore harsh environments on Earth and the Moon. 


\section{NextGen Community Participation}

NextGen members recognize that involvement in community activities is a critical responsibility of scientists and engineers; many planetary science activities rely on community input, and the value of early career individuals to this process is significant. Respondents to the NextGen survey indicated their participation in many different activities and roles in addition to their normal research (Figure 5); the survey allowed respondents to select as many activities as desired. The following sub-sections highlight several of the many ways that NextGen members contribute to the planetary science community.

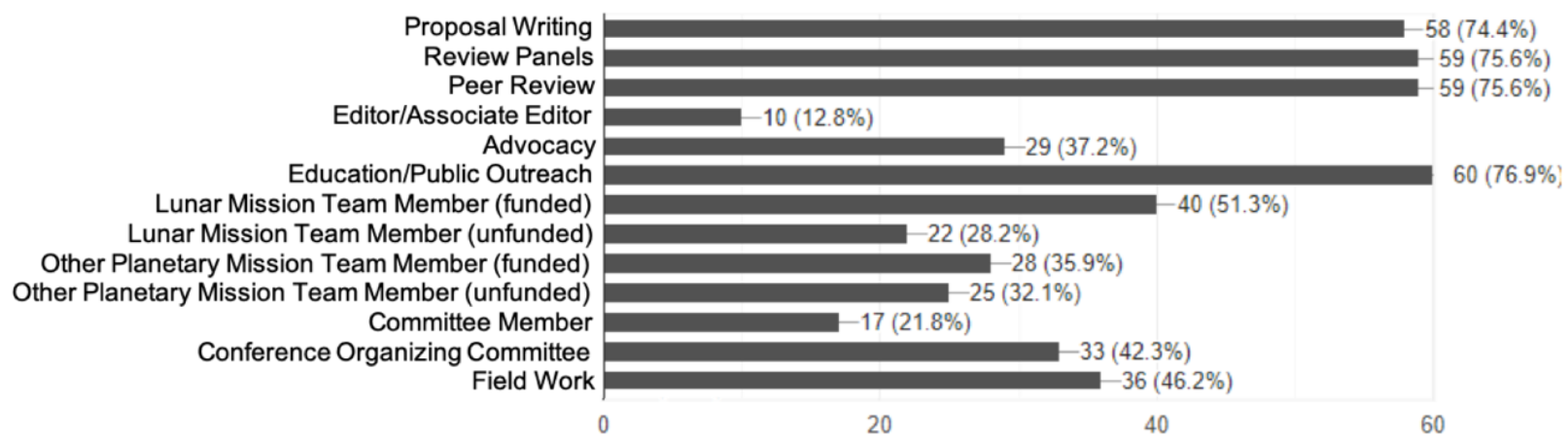

Figure 5: Self-Identified NextGen involvement with mission teams and other community activities. 91 individuals responded to this question, and the respondent was allowed to select more than one activity.

\subsection{Professional Contributions}

A large majority of survey respondents (74\%) are or have been actively involved in writing proposals as PI or Science PI (or "Future Investigator" for the FINESST program), and many (76\%) have served on review panels as either executive secretaries, panelists, or external reviewers. The peer review process is central to scientific communication and serving as a peer reviewer is a valuable way to contribute to the field. Approximately $76 \%$ of survey respondents have served as peer reviewers for journals, which is a significant percentage considering $19 \%$ of respondents are undergrad or grad students. $13 \%$ of respondents have also served as Editors or Associate Editors for various planetary science journals. Additionally, several NextGen members are actively involved in writing various chapters of the New Views of the Moon 2 book that is being submitted for publication in 2021.

More than a third of all survey participants have served on conference organizing committees, and many also serve on various committees or teams (e.g., the LEAG Executive Committee and LEAG Special Action Teams). The inclusion of early career professionals on such committees or teams gives NextGen members the opportunity to contribute to recommendations and decisions regarding future lunar robotic and 
human missions. The inclusion of early career professionals also ensures active engagement in discussions related to lunar science, technology, and exploration, in addition to providing these individuals with valuable experience as they continue on their career path.

NextGen members also participated in white papers for the 2023 Planetary Science and Astrobiology Decadal Survey. The survey produced by the National Academies informs various institutes of the current state of the scientific knowledge and prioritizes future missions. NextGen participation was vital to this effort as the early career scientists and engineers will be leading these missions in the future. The white papers submitted include topics about the state of lunar science with recent research advancements, the importance of lunar science to planetary science, planetary defense, and professional development. Additionally, several white papers with NextGen authors were submitted to the Artemis Science Definition Team. These white papers were used to define the scientific objectives of the Artemis III mission. These professional contributions to the Decadal Survey and the Artemis Science Definition Team served not only as a valuable experience for early career scientists and engineers, but also demonstrated that they are active in research and lunar exploration.

\subsection{Mission Involvement}

NextGen has a rich history of past and current planetary mission involvement, both on the funded and unfunded levels. Our members are involved with the ongoing LRO and ARTEMIS missions that are in lunar orbit, as well as the recent GRAIL, LADEE, Lunar Crater Observation and Sensing Satellite (LCROSS), and Chandrayaan-1 (which flew the US Moon Mineralogy Mapper, $\mathrm{M}^{3}$, instrument) lunar missions that are no longer operating. One of the founders of NextGen, Noah Petro, currently serves as the Project Scientist for LRO, and the Deputy PI for the Diviner instrument, Benjamin Greenhagen was one of the original members of NextGen. Kathleen Mandt, another NextGen member, serves as the Project Scientist for LRO's LAMP (Lyman-Alpha Mapping Project) instrument and as the LRO Volatile Theme Lead. The LRO Camera (LROC) Science Team also has many NextGen students, postdocs, and early-career scientists. A NextGen scientist, Prasun Mahanti, is the Deputy PI for ShadowCam, a camera that will fly on the Korean Lunar Pathfinder Orbiter, which will map reflectance in permanently shadowed regions and search or evidence of frost or ice deposits [67]. Another NextGen scientist, Julie Mitchell, currently serves as the Curator of Ices and Organics at Johnson Space Center, and supports the Astromaterials Curation Office 
efforts in lunar sample return and curation. Dr. Mitchell is also serving as the Artemis sample curator. In addition to NASA mission involvement, NextGen has involvement with several commercial companies who plan to go to the lunar surface, including Moon Express, Blue Origin, Astrobotic, and Masten.

Several upcoming lunar cubesats that will be flying on the first Artemis 1 Mission of the Space Launch System (SLS) have NextGen members on their science and engineering teams. Lunar Flashlight, which will map volatiles in permanently shadowed regions in the lunar South Pole [68], has NextGen Co-Is, and the Thermal Engineer for LunaH-map, which will map hydrogen at the South Pole [69], is a NextGen member.

NextGen maintains active involvement in mission concept design and in mission proposals. Many Discovery and New Frontiers class missions have included graduate students, postdocs, and early career professionals on their science and engineering teams. For example, the proposed New Frontiers class MoonRise lunar sample return mission [70][71] had substantial NextGen involvement on its science, engineering, and landing site safety teams. The PI for Moon Diver, a Discovery-class mission that would explore lunar pits [7], is a NextGen scientist, and many other NextGen scientists are actively involved in that mission concept. NextGen members are also involved with the Lunar Volatiles Orbiter, another Discovery-class mission concept that would carry surface and atmospheric composition instruments to address questions relating to volatile flows to and from the Moon [72]. Finally, many Planetary Mission Concept Studies (PMCS), including In Situ Geochronology for the Next Decade [그] , Intrepid [74], and the Lunar Geophysical Network [75] concepts, included NextGen members. These studies provide an invaluable onramp for early career scientists who may not have prior mission experience, or for those who desire more mission planning experience.

Many NextGen members are cross-disciplinary and also maintain research studies on other planetary worlds. Therefore, there is also significant NextGen involvement in other planetary missions, including in leadership positions. Non-lunar missions with NextGen participation include the MErcury Surface, Space ENvironment, GEochemistry, and Ranging (MESSENGER) mission, Mars2020, the Mars Science Laboratory (MSL), Mars Reconnaissance Orbiter (MRO), New Horizons to Pluto and the Kuiper Belt, Europa Clipper, and many others. Needless to say, NextGen has an active and thriving presence in planetary exploration, and we will continue striving to see that the young generation has a voice in the future of planetary missions. 


\subsection{Community Activities}

As a group centered around fostering and educating the next generation of lunar scientists and engineers, NextGen also values educating the public about lunar science and exploration and spreading excitement about planetary science in general. $77 \%$ of survey respondents are actively involved in education and public outreach, for age groups ranging from elementary school children to senior citizens. NextGen members have given talks to a wide variety of audiences, in a range of venues: astronomical societies, elementary, middle, and high schools, robotics clubs, library systems, museums, and many more. Outreach talks have centered on exploring the Moon from orbit using LRO, the $50^{\text {th }}$ Anniversary of Apollo, women in STEM (science, technology, engineering, and mathematics), remote sensing and adventures in the infrared, planetary robotic exploration, and more. Several NextGen members have also participated in other types of outreach activities, such as writing guest blog posts on their research and conference activities for the Planetary Society, discussing LRO and science activities on podcasts, by serving as science advisors to the SSERVI Exploration of the Moon and Asteroids by Secondary Students (ExMASS) program, and by serving as pen pals in the Letters to a Pre-Scientist program.

Decisions regarding lunar (and planetary) exploration are made by the government, driven by budgets, and influenced by individuals and industries. It is therefore essential that lunar scientists and engineers ensure that elected officials are aware of the incredible potential for technology development and scientific advances through continued space exploration. Having the voices of young scientists and engineers who are passionate about seeing the Moon at the forefront of Solar System exploration is vital to ensuring that Congress recognizes the importance of space exploration to our future, and that the necessary programs are funded. $37 \%$ of survey respondents are active in these advocacy efforts, although many respondents are government employees and are not permitted to participate in certain advocacy efforts, and several of NextGen members make regular trips to the US Capitol to speak directly with representatives. As part of the current and future workforce of NASA, academia, and industry, NextGen will remain active in space policy efforts.

\section{Conclusions}

For 13 years, NextGen has been training the current and future workforce for lunar exploration. NextGen has already made many significant contributions to the scientific and engineering community, and the group is committed to continuing to foster the 
next generation of researchers, engineers, and explorers. Below is a short list summarizing key concepts:

- The Next Generation Lunar Scientists and Engineers group is a vibrant, active community of young professionals and students who are committed to seeing the Moon remain a primary target of planetary science and exploration. NextGen is dedicated to producing productive members of the lunar science and engineering communities through professional development workshops and scientific research, and who are able to build and contribute to a sustainable lunar science and exploration program. NextGen offers tools, training, and opportunities for students and early career professionals to become effective leaders under the tutelage of senior scientists and engineers.

- NextGen members are engaged in education and public outreach, scientific research, and advocacy, and continually contribute to the scientific community by serving on review panels, as peer reviewers, and on conference organizing committees.

- NextGen is the future workforce of NASA, academia, and industry. It is therefore imperative that continued support be provided from the lunar community to foster the growth of students and early career professionals. This support can come in many forms, including, but not limited to: opportunities to serve as Co-Investigators on mission teams, inclusion on committees, advisory boards, and special action teams, and increased travel funding for attendance at professional conferences, workshops, and mission team meetings, and opportunities to lead (as PI) on competed scientific proposals.

Acknowledgments: NextGen would first and foremost like to thank all of our members for their valuable feedback and contributions to ensuring our group remains beneficial to the community. We would also like to thank SSERVI and LEAG, specifically Gregory Schmidt, Brad Bailey, Yvonne Pendleton, Clive Neal, and Samuel Lawrence for their continued support of NextGen. We extend thanks to all of the scientists and engineers who have contributed their time to serve as panelists at our workshops. We thank the former NASA SMD EPOESS program for providing financial support for the inaugural NextGen workshop, and we thank NASA for supporting young scientists and engineers. Any use of trade, firm, or product names is for descriptive purposes only and does not imply endorsement by the U.S. Government. The survey conducted for this publication is not part of a systematic scientific investigation; therefore, IRB approval is not required per direction from the Washington University in St. Louis Human Resource Protection Office, nor is advanced 
approval by the Office of Management and Budget (OMB) required since the survey was initiated by a volunteer organization and not by the USGS or any other federal agency.

\section{Citations}

1. Petro, N.; Bleacher, L.; Bleacher, J.; Noble, S.; Cahill, K.R.S.; Fagan, A.; Mader, M.; Shankar, B. Towards a Sustainable Lunar Science Community: Developing the Next Generations of Lunar Scientists and Engineers. Annual Meeting of the Lunar Exploration Analysis Group; Houston, TX, 2009; Vol. 1515, p. $53 \subseteq$

2. Petro, N.E.; Bleacher, L.; Bleacher, J.E.; Santiago, D.; Noble, S.K. Next Generation Lunar Scientists and Engineers Group: EPO for the NextGen. In AGU Fall Meeting Abstracts; San Francisco, CA, 2010; Vol. 31, Abstract ED31B-0620.

3. Bleacher, L.V.; Petro, N.; Bleacher, J.E.; Santiago, D.; Noble, S. Next Generation Lunar Scientists and Engineers: Developing the Future Work Force for a Sustainable Lunar Science and Exploration Program. 42nd Lunar and Planetary Science Conference; The Woodlands, TX, 2011; Abstract \#1408. $\subseteq$

4. Clegg-Watkins, R.N.; Valencia, S.N.; Runyon, K. Bridging the Lunar Generation Gap: NextGen and LEAG. Annual Meeting of the Lunar Exploration Analysis Group; Columbia, MD, 2015; Vol. 1863, p. 2017.

5. Bouchard, M.; Stein, N.; McConnell, H.; Settle, B.; Lazecheko, S.; Kelley, M.; Zanetti, M.; Agarwal, R. Systems Engineering for the Design and Fabrication of a Screw-Propelled Automated Martian Regolith Collector Robot. Frontiers in Aerospace Engineering, 2016. $\uplus$

6. Clegg-Watkins, R.N.; Joliff, B.L.; Watkins, M.J.; Coman, E.; Giguere, T.A.; Stopar, J.D.; Lawrence, S.J.; Nonmare volcanism on the Moon: Photometric evidence for the presence of evolved silicic materials. Icarus 2017, 285, 169-184, doi:10.1016/j.icarus.2016.12.004. 7. Kerber, L.; Nesnas, I.; Keszthelyi, L.; Head, J.W.; Denevi, B.; Hayne, P.O.; Mitchell, K.; Ashley, J.W.; Whitten, J.L.; Stickle, A.M.; et al. Moon Diver: A Discovery Mission Concept for Understanding the History of the Mare Basalts Through the Exploration of a Lunar Mare Pit. 49th Lunar and Planetary Science Conference; The Woodlands, TX, 2018; Abstract \#1956. 
8. Meyer, H.M.; Hawke, B.R.; Giguere, T.A.; Robinson, M.S. Lunar Light Plains and Cryptomaria Southwest of Orientale. 46th Lunar and Planetary Science Conference; The Woodlands, TX, 2015; Abstract \#1692. $\subseteq$

9. Clegg-Watkins, R.N.; Jolliff, B.L.; Petro, N.E.; Lawrence, S.J. The Distribution of Mare and Cryptomare in the South Pole-Aitken Basin: New Perspectives from Multiple Datasets. 47th Lunar and Planetary Science Conference; The Woodlands, TX, 2016; Abstract \#2072. $\subseteq$

10. Valencia, S.N.; Watkins, R.N.; Moriarty, D.P.; Jolliff, B.L.; Petro, N.E. Surface Composition and Mineralogy of the Appenine Bench Formation. 51 ${ }^{\text {st }}$ Lunar and Planetary Science Conference; The Woodlands, TX, 2020; Abstract \#2293. 11. Jawin, E.R.; Head, J.W.; Cannon, K.M. Spectral Unmixing Modeling of the Aristarchus Pyroclastic Deposit: Assessing Eruptive History and Exploration Potential of Glass-Rich Regional Lunar Pyroclastic Deposits.; 2017 Annual Meeting of the Lunar Exploration Analysis Group Abstract \#5052. 12. Jawin, E.R.; Besse, S.; Gaddis, L.R.; Sunshine, J.M.; Head, J.W.; Mazrouei, S. Examining spectral variations in localized lunar dark mantle deposits. Journal of Geophysical Research: Planets 2015, 120, 1310-1331, doi:10.1002/2014JE004759. 13. Jawin, E.R.; Kiefer, W.S.; Fassett, C.I.; Bussey, D.B.J.; Cahill, J.T.S.; Dyar, M.D.; Lawrence, S.J.; Spudis, P.D. The relationship between radar scattering and surface roughness of lunar volcanic features. Journal of Geophysical Research: Planets 2014, 119, 2331-2348, doi:10.1002/2014JE004668.

14. Jawin, E.R.; Head, J.W. Assessing the Volcanic History of the Prinz-Harbinger Region Using Radar and Spectroscopy. $49^{\text {th }}$ Lunar and Planetary Science Conference; 2018; Abstract \#1237.

15. Dhingra, D.; Head, J.W.; Pieters, C.M. Geological mapping of impact melt deposits at lunar complex craters Jackson and Tycho: Morphologic and topographic diversity and relation to the cratering process. Icarus 2017, 283, 268-281, doi:10.1016/j.icarus.2016.05.004. $\subseteq$ 16. Meyer, H.M.; Robinson, M.S.; Stopar, J.D. A New Look at Surveyor VII from the Lunar Reconnaissance Orbiter Camera. $48^{\text {th }}$ Lunar and Planetary Science Conference; The Woodlands, TX, 2017; Abstract \#2631. 
17. Runyon, K.D.; Moriarty, D.P.; Denevi, B.W.; Greenhagen, B.T.; Morgan, G.; Young, K.E.; Cohen, B.A.; Bogert, C.H. van der; Hiesinger, H.; Jozwiak, L.M. Impact Melt Facies in the Moon's Crisium Basin: Identifying, Characterizing, and Future Radiogenic Dating. Journal of Geophysical Research: Planets 2020, 125, e2019JE006024, doi:https://doi.org/10.1029/2019JE006024.

18. Ostrach, L.R. Impact-Related Processes on Mercury and the Moon. Ph.D. Thesis 2013. $\leftrightarrows$

19. Ostrach, L.R.; Robinson, M.S.; Denevi, B.W. Distribution of Impact Melt on Mercury and the Moon. 43rd Lunar and Planetary Science Conference; The Woodlands, TX, 2012; Abstract \#1113.

20. Povilaitis, R.Z.; Robinson, M.S.; van der Bogert, C.H.; Hiesinger, H.; Meyer, H.M.; Ostrach, L.R. Crater density differences: Exploring regional resurfacing, secondary crater populations, and crater saturation equilibrium on the moon. Planetary and Space Science 2017, doi:10.1016/j.pss.2017.05.006. 21. Meyer, H.M.; Denevi, B.W.; Boyd, A.K.; Robinson, M.S. The distribution and origin of lunar light plains around Orientale basin. Icarus 2016, 273, 135-145, doi:10.1016/j.icarus.2016.02.014. $\subseteq$

22. Ostrach, L.R.; Robinson, M.S.; Denevi, B.W.; Thomas, P.C. Effects of Incidence Angle on Crater Counting Observations. 42nd Lunar and Planetary Science Conference; The Woodlands, TX, 2011; Abstract \#1202. $\Perp$ 23. Ostrach, L.R.; Thomas, P.C. Effects of illumination on relative and absolute dating of planetary surfaces. in prep. $\subseteq$

24. Meyer, H.; Mahanti, P.; Robinson, M.; Povilaitis, R. Quantifying Slope Effects and Variations in Crater Density across a Single Geologic Unit. In Proceedings of the AAS/Division for Planetary Sciences Meeting Abstracts \#48; Pasadena, CA, 2016; Abstract 223.04. $\subseteq$

25. Ostrach, L.R.; Robinson, M.S. Areal Crater Density Analysis of Volcanic Smooth Plains: Mare Imbrium, a Revised Approach. In 45th Lunar and Planetary Science Conference; The Woodlands, TX, 2014; Abstract \#1266. $\subseteq$ 26. Ostrach, L.R.; Robinson, M.S. Using Crater Size-Frequency Measurements to Distinguish Age Units Within Volcanic Smooth Plains - A New Approach. 44th Lunar and Planetary Science Conference; The Woodlands, TX, 2013; Abstract \#1086. 
27. Ostrach, L.R.; Singer, K.N.; Robinson, M.S. Non-Obvious Secondary Crater Detection on the Moon. 46th Lunar and Planetary Science Conference; The Woodlands, TX, 2015; Abstract \#1082. $匚$ 28. Mahanti, P.; Robinson, M.S.; Humm, D.C.; Stopar, J.D. A standardized approach for quantitative characterization of impact crater topography. Icarus 2014, 241, 114129, doi:10.1016/j.icarus.2014.06.023.

29. Mahanti, P.; Robinson, M.S.; Thompson, T.J.; Henriksen, M.R. Small lunar craters at the Apollo 16 and 17 landing sites - morphology and degradation. Icarus 2018, 299, 475-501, doi:10.1016/j.icarus.2017.08.018.

30. Meyer, H.M.; Denevi, B.W.; Robinson, M.S.; Boyd, A.K. The Global Distribution of Lunar Light Plains From the Lunar Reconnaissance Orbiter Camera. Journal of Geophysical Research: Planets 2020, 125, e2019JE006073, doi:https://doi.org/10.1029/2019JE006073. 31. Dhingra, D.; Pieters, C.M.; Boardman, J.W.; Head, J.W.; Isaacson, P.J.; Taylor, L.A. Compositional diversity at Theophilus Crater: Understanding the geological context of Mg-spinel bearing central peaks: Mg-SPINEL AT THEOPHILUS. Geophysical Research Letters 2011, 38, n/a-n/a, doi:10.1029/2011GL047314. 32. Dhingra, D.; Pieters, C.M.; Head, J.W.; Isaacson, P.J. Large mineralogically distinct impact melt feature at Copernicus crater - Evidence for retention of compositional heterogeneity: IMPACT MELT MINERALOGICAL HETEROGENEITY. Geophys. Res. Lett. 2013, 40, 1043-1048, doi:10.1002/grl.50255. 33. Moriarty, D.P.; Pieters, C.M.; Isaacson, P.J. Compositional heterogeneity of central peaks within the South Pole-Aitken Basin: SPA CENTRAL PEAK HETEROGENEITY. J. Geophys. Res-Planet 2013, 118, 2310-2322, doi:10.1002/2013JE004376. $\uplus$ 34. Moriarty, D.P.; Pieters, C.M. The nature and origin of Mafic Mound in the South Pole-Aitken Basin: Mafic Mound: Nature and Origin. Geophys. Res. Lett. 2015, 42, 7907-7915, doi:10.1002/2015GL065718.

35. Moriarty, D.P.; Pieters, C.M. The Character of South Pole-Aitken Basin: Patterns of Surface and Subsurface Composition. J. Geophys. Res-Planet 2018, 123, 729-747, doi:10.1002/2017JE005364. $\leftrightarrows$

36. Lemelin, M.; Lucey, P.G.; Miljković, K.; Gaddis, L.R.; Hare, T.; Ohtake, M. The compositions of the lunar crust and upper mantle: Spectral analysis of the inner 
rings of lunar impact basins. Planetary and Space Science2019, 165, 230-243, doi:10.1016/j.pss.2018.10.003. 37. Lemelin, M.; Lucey, P.G.; Song, E.; Taylor, G.J. Lunar central peak mineralogy and iron content using the Kaguya Multiband Imager: Reassessment of the compositional structure of the lunar crust. Journal of Geophysical Research: Planets 2015, 120, 869-887, doi:https://doi.org/10.1002/2014JE004778. 38. Fuqua-Haviland, H.; Fatemi, S.; Poppe, A.R.; Delory, G.T.; de Pater, I.; Grimm, R.E. Multi-Model Approach for ARTEMIS Time Domain Electromagnetic Sounding Analysis of the Moon. 48th Lunar and Planetary Science Conference; The Woodlands, TX, 2017; Abstract \#2604.

39. Fuqua Haviland, H.; Poppe, A.R.; Fatemi, S.; Delory, G.T. Improved Methods for Time Domain Electromagnetic Sounding of the Moon. 49th Lunar and Planetary Science Conference; The Woodlands, TX, 2018; Abstract \#2891. 40. Greenhagen, B.T.; Lucey, P.G.; Wyatt, M.B.; Glotch, T.D.; Allen, C.C.; Arnold, J.A.; Bandfield, J.L.; Bowles, N.E.; Hanna, K.L.D.; Hayne, P.O.; et al. Global Silicate Mineralogy of the Moon from the Diviner Lunar Radiometer. Science 2010, 329, 1507-1509, doi:10.1126/science.1192196.

41. Greenhagen, B.T.; Neish, C.D.; Williams, J.-P.; Cahill, J.T.S.; Ghent, R.R.; Hayne, P.O.; Lawrence, S.J.; Petro, N.E.; Bandfield, J.L. Origin of the anomalously rocky appearance of Tsiolkovskiy crater. Icarus 2016, 273, 237-247, doi:10.1016/j.icarus.2016.02.041. 42. Vasavada, A.R.; Bandfield, J.L.; Greenhagen, B.T.; Hayne, P.O.; Siegler, M.A.; Williams, J.-P.; Paige, D.A. Lunar equatorial surface temperatures and regolith properties from the Diviner Lunar Radiometer Experiment: LUNAR EQUATORIAL REGOLITH PROPERTIES. J. Geophys. Res-Planet 2012, 117, n/a-n/a, doi:10.1029/2011JE003987.

43. Tucker, O.J.; Farrell, W.M.; Killen, R.M.; Hurley, D.M. Solar Wind Implantation into Lunar Regolith II: Monte Carlo Simulations of Hydrogen Retention in a Surface with Defects and the Hydrogen (H, H2) Exosphere.49th Lunar and Planetary Science Conference; The Woodlands, TX, 2018; Abstract \#2549. $\_$ 44. Prem, P.; Artemieva, N.A.; Goldstein, D.B.; Varghese, P.L.; Trafton, L.M. Transport of water in a transient impact-generated lunar atmosphere. Icarus $\mathbf{2 0 1 5}$, $255,148-$ 
158, doi:10.1016/j.icarus.2014.10.017.

45. Prem, P.; Goldstein, D.B.; Varghese, P.L.; Trafton, L.M. The influence of surface roughness on volatile transport on the Moon. Icarus 2018, 299, 31-45, doi:10.1016/j.icarus.2017.07.010.

46. Poston, M.J.; Grieves, G.A.; Aleksandrov, A.B.; Hibbitts, C.A.; Dyar, M.D.; Orlando, T.M. Temperature programmed desorption studies of water interactions with Apollo lunar samples 12001 and 72501. Icarus 2015, 255, 24-29, doi:10.1016/j.icarus.2014.09.049. 47. Bandfield, J.L.; Poston, M.J.; Klima, R.L.; Edwards, C.S. Widespread distribution of $\mathrm{OH} / \mathrm{H} 2 \mathrm{O}$ on the lunar surface inferred from spectral data. Nat. Geosci. 2018, 11, 173-177, doi:10.1038/s41561-018-0065-0. ㅌ

48. Farrell, W.M.; Hurley, D.M.; Poston, M.J.; Hayne, P.O.; McLain, J.L. Cold Trapping of Lunar Polar Crater Volatiles: A Model of Desorption from Frosty Grains. 49th Lunar and Planetary Science Conference; 2018; Abstract \#2254. 49. Mitchell, J.; Lawrence, S.; Robinson, M.; Speyerer, E.; Denevi, B. Using complementary remote sensing techniques to assess the presence of volatiles at the lunar north pole. Planet. Space Sci. 2017, doi:10.1016/j.pss.2017.07.015. 50. Mitchell, J.L.; Fries, M.D.; Zeigler, R.A.; McCubbin, F.M. New Challenges in the Curation of Cold, Volatile-Rich Extraterrestrial Samples. $49^{\text {th }}$ Lunar and Planetary Science Conference; The Woodlands, TX, 2018; Abstract \#1019. 51. Mandt, K.E.; Greathouse, T.K.; Retherford, K.D.; Randall Gladstone, G.; Jordan, A.P.; Lemelin, M.; Koeber, S.D.; Bowman-Cisneros, E.; Wesley Patterson, G.; Robinson, M.; et al. LRO-LAMP detection of geologically young craters within lunar permanently shaded regions. Icarus 2016, 273, 114-120, doi:10.1016/j.icarus.2015.07.031. 52. Lemelin, M.; Lucey, P.G.; Neumann, G.A.; Mazarico, E.M.; Barker, M.K.; Kakazu, A.; Trang, D.; Smith, D.E.; Zuber, M.T. Improved calibration of reflectance data from the LRO Lunar Orbiter Laser Altimeter (LOLA) and implications for space weathering. Icarus 2016, 273, 315-328, doi:10.1016/j.icarus.2016.02.006. 53. Watkins, R.N.; Jolliff, B.L.; Mistick, K.; Fogerty, C.; Lawrence, S.J.; Singer, K.N.; Ghent, R.R. Boulder Distributions Around Young, Small Lunar Impact Craters and Implications for Regolith Production Rates and Landing Site Safety. Journal of 
Geophysical Research: Planets 2019, 124, 2754-2771, doi:https://doi.org/10.1029/2019JE005963. 54. Mazrouei, S.; Ghent, R.R. Towards an Understanding of Initial Crater Rock Populations: Boulder Distribution Around Copernicus Crater. 48th Lunar and Planetary Science Conference; 2017; Abstract \#2507. $\_$

55. Ostrach, L.R. Effects of shaking on density sorting in granular materials: Implications for planetary regoliths. Icarus in revision. $\_$ 56. Clegg, R.N.; Jolliff, B.L.; Robinson, M.S.; Hapke, B.W.; Plescia, J.B. Effects of rocket exhaust on lunar soil reflectance properties. Icarus 2014, 227, 176-194, doi:10.1016/j.icarus.2013.09.013.

57. Clegg-Watkins, R.N.; Jolliff, B.L.; Boyd, A.; Robinson, M.S.; Wagner, R.; Stopar, J.D.; Plescia, J.B.; Speyerer, E.J. Photometric characterization of the Chang'e-3 landing site using LROC NAC images. Icarus 2016, 273, 84-95, doi:10.1016/j.icarus.2015.12.010.

58. Fagan, A.L.; Neal, C.R.; Simonetti, A.; Donohue, P.H.; O’Sullivan, K.M. Distinguishing between Apollo 14 impact melt and pristine mare basalt samples by geochemical and textural analyses of olivine. Geochimica et Cosmochimica Acta 2013, 106, 429-445, doi:10.1016/j.gca.2012.12.032.

59. Fagan, A.L.; Neal, C.R. A new lunar high-Ti basalt type defined from clasts in Apollo 16 breccia 60639. Geochimica et Cosmochimica Acta 2016, 173, 352-372, doi:10.1016/j.gca.2015.08.007. 60. Fagan, A.L.; Joy, K.H.; Bogard, D.D.; Kring, D.A. Ages of Globally Distributed Lunar Paleoregoliths and Soils from 3.9 Ga to the Present. Earth, Moon, and Planets 2014, 112, 59-71, doi:10.1007/s11038-014-9437-7. 트 61. Valencia, S.N.; Jolliff, B.L.; Korotev, R.L. Petrography, relationships, and petrogenesis of the gabbroic lithologies in Northwest Africa 773 clan members Northwest Africa 773, 2727, 3160, 3170, 7007, and 10656. Meteoritics \& Planetary Science 2019, 54, 2083-2115, doi:https://doi.org/10.1111/maps.13370. 62. Valencia, S.N.; Jolliff, B.L.; Korotev, R.L.; Seddio, S.M. New Compositional Data for Apollo 12 Samples 12013 and 12033: Insights into Proto-Lithologies. 46th Lunar and Planetary Science Conference; The Woodlands, TX, 2015; Abstract \#2884. 
63. Valencia, S.N.; Jolliff, B.L.; Korotev, R.L. Petrography and Chemistry of the Mafic and REE-Rich Components in Apollo Sample 12013. 47th Lunar and Planetary Science Conference; The Woodlands, TX, 2016; Abstract \#2361. 64. Thiemens, M.M.; Sprung, P.; Fonseca, R.O.C.; Leitzke, F.P.; Münker, C. Early Moon formation inferred from hafnium-tungsten systematics. Nature Geoscience 2019, 12, 696-700, doi:10.1038/s41561-019-0398-3.

65. Young, K.; Hurtado, J.M.; Bleacher, J.E.; Brent Garry, W.; Bleisath, S.; Buffington, J.; Rice, J.W. Tools and technologies needed for conducting planetary field geology while on EVA: Insights from the 2010 Desert RATS geologist crewmembers. Acta Astronaut. 2013, 90, 332-343, doi:10.1016/j.actaastro.2011.10.016. 66. Young, K.E.; Graff, T.G.; Coan, D.; Reagan, M.; Todd, W.; Naids, A.; Walker, M.; Hood, A.; Dougan, K.E.; Bellantuono, A.; et al. Conducting Science-Driven Extravehicular Activities During Planetary Surface Exploration - The NEEMO (NASA Extreme Environment Mission Operations) 22 Mission. 49th Lunar and Planetary Science Conference; The Woodlands, TX, 2018; Abstract \#2422. 67. Robinson, M.S.; Mahanti, P.; Carter, L.M.; Denevi, B.W.; Estes, N.M.; Ravine, M.A.; Speyerer, E.J.; Wagner, R.V. ShadowCam - Seeing in the Dark. European Planetary Science Congress; Riga, Latvia, 2017; Abstract \#EPSC2017-506. 68. Cohen, B.A.; Hayne, P.O.; Greenhagen, B.T.; Paige, D.A. Lunar Flashlight: Exploration and Science at the Moon with a 6U Cubesat. AGU Fall Meeting Abstracts 2015, 52, EP52B-07. 69. Hardgrove, C.; Bell, J.; Thangavelautham, J.; Klesh, A.; Starr, R.; Colaprete, T.; Robinson, M.; Drake, D.; Johnson, E.; Christian, J.; et al. The Lunar Polar Hydrogen Mapper (LunaH-Map) Mission: Mapping Hydrogen Distributions in Permanently Shadowed Regions of the Moon's South Pole. Annual Meeting of the Lunar Exploration Analysis Group, 2015; Abstract \#2035. 70. Jolliff, B.L.; Shearer, C.K.; Papanastassiou, D.A.; Liu, Y.; MoonRise Science Team Why Do We Need Samples from the Moon's South Pole-Aitken Basin and What Would We Do with Them? $48^{\text {th }}$ Lunar and Planetary Science Conference; The Woodlands, TX, 2017; Abstract \#1300.

71. Jolliff, B.L.; Watkins, R.C.; Petro, N.E.; Moriarty, D.P.; Lawrence, S.J.; Head, J.W.; Pieters, C.M.; Hagerty, J.J.; Fergason, R.L.; Hare, T.M.; et al. Selecting and Certifying 
Landing Sites for MoonRise in South Pole-Aitken Basin. 48th Lunar and Planetary Science Conference; The Woodlands, TX, 2017; Abstract \#1326. $\subseteq$

72. Lucey, P.G.; Petro, N.E.; Hurley, D.; Farrell, W.; Sun, X.; Green, R.; Greenberger, R.; Cameron, D. The Lunar Volatiles Orbiter: A Lunar Discovery Mission Concept. Annual Meeting of the Lunar Exploration Analysis Group; Columbia, MD, 2017; Abstract \#5048. $匚$

73. Cohen, B.A. Geochronology for the Next Decade. Annual Meeting of the Lunar Exploration Analysis Group; Washington, D.C., 2019; Abstract \#5027.

74. Robinson, M. Intrepid: The Next Generation of Lunar Exploration. Annual Meeting of the Lunar Exploration Analysis Group; Washington, D.C., 2019; Abstract \#5049. $\subseteq$

75. Neal, C.R.; Weber, R.; LGN Team Establishing a Long-Lived, Global Lunar Geophysical Network (LGN). Annual Meeting of the Lunar Exploration Analysis Group; Washington, D.C., 2019; Abstract \#5067. 